\title{
Hopelessness Leading to Self-harm and Suicide
}

\section{Abstract}

Hopelessness has become of the common reason behind suicide. People who are disturbed and have commonly seen with presence of suicidal ideation or continuous experiences of self-harming have hopelessness in background. This is very essential to understand the mechanism of stress and its connection with hopelessness because of ineffective coping or lack of strong understanding in coping skills. Common presence of hopelessness is harmful and provides difficult situations in individual and families where results are ending lives or self-harming. At the end families have to join hands with health care providers to work on how to improve positive behavior and ignite hope among these people. Such kind of strategic endeavors can save live, build a hopeful society and bring a positive mental health change.

Keywords: Hopelessness; Self-harm; Suicide; Mental health

Received: January 11, 2019; Accepted: March 19, 2019; Published: March 23, 2019

\section{Introduction}

People react distinctively to the troubles or stressors in life. Some people stay strong to face all challenges and some who are not able to face these challenges or not able to cope with stressors usually become victim of hopelessness and deliberately ending their lives [1]. Hopelessness is a feeling characterized by absence or insufficiency of hope [2]. It is conceptualized that individual who experience hopelessness usually have pessimistic expectation or no expectations for future [3]. Hopelessness often leads to low mood and negatively impact one's ability to perceive oneself, other people and surroundings [2]. Hopelessness is the leading cause of suicide and many people around the globe experienced hopelessness and attempted suicide because of it $[4,5]$.

Similarly, some of the researches done in South Asia support and evidenced the presence of hopelessness in clients ending up with suicidal ideation or suicide [6]. This is seen that presence of hopelessness is one of the dominant risk factors among people harming self or ending lives through suicides $[5,7]$. A survey was conducted in Pakistan between years of 2015-2016, showed that more than 300 people per year experience hopelessness due to unemployment, family conflicts, extreme poverty and health problems [7]. This situation creates a lot of burden in individuals' lives and coping with stress becomes impossible for them, ultimately their results are depression or hopelessness leading to self-harm or suicide in majority of the cases [8].

In our clinical practice as student nurses we more or less observe same kind of situation where hopelessness is common among

\section{Shumaila Khadim Ali ${ }^{1}$ and Sarmad Muhammad Soomar ${ }^{2 *}$}

\author{
1 Student, School of Nursing Aga Khan \\ University Pakistan \\ 2 Senior Research Assistant, Psychiatry, \\ Aga Khan University Pakistan
}

\section{*Corresponding author: \\ Dr. Sarmad Muhammad Soomar Ranani \\ soomarsarmad@gmail.com \\ Department of Nursing Services, Aga Khan University School of Nursing and Midwifery, Pakistan.}

Tel: +923322383509

Citation: Ali SK, Soomar SM (2019)

Hopelessness Leading to Self-harm and

Suicide. J Neurol Neurosci Vol.10 No.2:296.

victims of deliberate self-harm. There were lot more into the stories of these people to understand and empathize. We personally observed this momentum of hopelessness in mentally ill clients at various tertiary mental health settings in Karachi, Pakistan. Reasons for hopelessness and ending lives ultimately or harming self, mostly include long-lasting illnesses and physical disorders that limits one's activity and movement. Other social factors include loss of so-called dignity, living in stigmas, un employment, family conflicts and issues, or other financial constrains [9].

\section{Theory of Hopelessness}

Abramson, Metalsky \& Alloy proposed a theory related to hopelessness [10]. According to this theory due to any life circumstances individual develop negative view for their own self. He or she assumes himself or herself as worthless person. In addition, negative perception for others starts building in with the passage of time. Later, person starts developing negative views or negative expectations for future. All these negative perception for oneself, others and future leads to hopelessness, which often results in self-harming behaviors. This may be a common beginning in clients suffering from mental illness but not necessarily seen in everyone.

In clinical setup we have most of the time seen clients who consider themselves worthless. In communicating with them it is 
easily observed that they possess no goals or realistic expectations for future and suicidal ideations are highly observed from their behaviors, communication and clues. This is also observed that with time they not only hate themselves but have issues with family, other people and surroundings.

\section{Discussion on the Strategies}

We as nurses try to encourage and motivate them and involve psychologist to make a proper goal planner for them. Also, prevention and cautions are maintained in clinical setup to reduce risk of suicide and similar teaching is given to family members. There are several other strategies recommended to develop positivity and hope in these clients. Such as identifying client's strengths, appreciating on little or small achievements and discussing past achievements, can help develop hope. Encouraging clients to take timely medications was also a strong action appended by nurses.

Communication plays an important role, because therapeutic communication can help to build trust worthy relationship with person, which help care givers to interact and engage them in

\section{References}

1 Jenny M, Brian T, Samuel H, Paul F (2015) Hope and hopelessness: The role of hope in buffering the impact of hopelessness on suicidal ideations. PLoS One 10: e0130073

2 Hanna D, White R, Lyons K, Mc Parland J, Shannon C, et al. (2011) The structure of the beck hopelessness scale: A confirmatory factor analysis in UK students. Personality and Individual Differences 51: 17-22.

3 Marsiglia F, Kulis S, Parsai M (2011) Hopelessness, family stress, and depression among Mexican-heritage mothers in south west. Health Soc Work 36: 7-18.

4 Britton PC, Duberstein PR, Conner KR, Heisel MJ, Hirsch JK (2008) Reason for living, hopelessness, and suicidal ideation among depressed adults 50 years or older. Am J Geriatr Psychiatry 16: 736-741. different activities that will be beneficial for his or her mental well-being. We also try most of them time to build better communications with clients and encourage other health care professionals to do so.

Also, our most emphasis is on family meetings and training where we develop their understanding of the problem and enrich their capacities to develop hope and positivity in person when he or she moves to home. We train families to develop environment at home and improve their own communication to enhance the person's positive behavior.

\section{Conclusion}

Hopelessness leading to self-harm and suicide is a serious issue around the globe. It should be managed by using several strategies because it can negatively influence one's thoughts, feelings and perception for self and others. It is highly important for families and health care providers to engage in the client's development and show their own positive role in the transformation required in client. Strategic endeavors involving families with healthcare staff can save lives, build a hopeful society and bring a positive mental health change in people.

5 Sokero P, Eerola M, Rytsälä H, Melartin T, Leskelä U, et al. (2006) Decline in suicidal ideation among patients with MDD is preceded by decline in depression and hopelessness. J Affect Disord 95: 95-102.

6 Shidhaye R, Gangale S, Patel V (2016) Prevalence and treatment coverage for depression: A population-based survey in Vidarbha, India. Soc Psychiatry Psychiatr Epidemiol 51: 993-1003.

7 Adnan D (2017) Rising suicide cases: Pakistan observer.

8 Rehman A (2018) Over 300,000 at risk of committing suicide in Pakistan.

9 Cynthia L (2011) Experience of depression: Hopelessness.

10 Liu RT, Kleiman EM, Nestor BA, Cheek SM (2015) The hopelessness theory of depression: A quarter-century in review. Clin Psychol (New York, USA) 22: 345-365. 